Revue bibliographique pour le domaine irano-aryen

\title{
Nobuaki Kondo. Islamic Law and Society in Iran (a social history of Qajar Tehran)
}

\section{Alisa Shablovskaia}

\section{(2) OpenEdition}

9 Journals

\section{Édition électronique}

URL : http://journals.openedition.org/abstractairanica/50322

DOI : 10.4000/abstractairanica.50322

ISBN : 1961-960X

ISSN : 1961-960X

Éditeur :

CNRS (UMR 7528 Mondes iraniens et indiens), Éditions de l'IFRI

Référence électronique

Alisa Shablovskaia, « Nobuaki Kondo. Islamic Law and Society in Iran (a social history of Qajar Tehran)», Abstracta Iranica [En ligne], Volume 40-41 | 2019, document 2, mis en ligne le 30 décembre 2019, consulté le 20 avril 2021. URL : http://journals.openedition.org/abstractairanica/50322 ; DOI : https:// doi.org/10.4000/abstractairanica.50322

Ce document a été généré automatiquement le 20 avril 2021.

Tous droits réservés 


\title{
Nobuaki Kondo. Islamic Law and Society in Iran (a social history of Qajar Tehran)
}

\author{
Alisa Shablovskaia
}

\section{RÉFÉRENCE}

Nobuaki Kondo. Islamic Law and Society in Iran (a social history of Qajar Tehran). London :

Routledge, 2017, 210 p.

1 Cet ouvrage de Nobuaki Kondo représente une contribution majeure aux champs d'études du système judiciaire qajar et des fondations pieuses de mainmorte (vaqf) dans le contexte urbain. L'auteur exploite une riche documentation en persan qui contient des documents privés, des rapports administratifs, des inventaires de propriété, des livres fiscaux ainsi que les registres inédits des deux juristes-théologiens (mojtahed) Shaykh Fazlolllah Nuri (m. 1909) et Sayyed Mohammad Sadeq Sangelaji (m. 1883) - ce qui fait de son ouvrage une étude exemplaire des sources primaires de l'époque qajar. En examinant l'opposition sharīa/orf (deux termes arabo-persans traditionnellement désignant les sources du droit islamiques et non islamiques), l'auteur s'engage dans un dialogue avec d'autres spécialistes du sujet (tels que William Floor, Irene Schneider et Christoph Werner) et s'appuie sur l'interprétation de l'orf comme pouvoir exécutif de Werner. L'ouvrage est divisé en huit chapitres : dans le premier chapitre, Kondo retrace l'évolution des institutions administratives de Téhéran au XIX ${ }^{\mathrm{e}}$ siècle; dans le deuxième chapitre, l'auteur développe sa thèse principale stipulant que la sharīa était le seul standard légal dans la société qajar, tandis que le terme d'orf faisait référence au pouvoir exécutif dont les cours des mojtahed étaient dépourvues; les chapitres 3 à 5 sont consacrés aux spécificités des cours «judiciaires » présidées par les mojtahid dont la fonction principale est présentée comme la rédaction et la validation des documents légaux; les trois derniers chapitres traitent de l'institution du vaqf et son rôle instrumental dans l'entretien de l'espace public par la communauté musulmane ainsi 
que dans l'expansion urbaine de Téhéran au XIXe siècle. Grâce à son analyse nuancée de la documentation en persan, l'auteur parvient à exposer d'une manière très claire les difficultés liées à l'interprétation des pratiques légales en Iran de la période qajar.

L'argumentation et la structure de l'ouvrage restent cependant sujettes à de multiples interrogations. Le rejet, probablement judicieux, du concept de l'orf comme droit coutumier ne s'appuie pas sur une analyse critique des sources primaires qui revendiquent cette définition de l'orf. Les imbrications des traditions locales, du contexte politique et des préceptes de la sharīa sont ainsi délaissées à la faveur d'une opposition binaire entre les cours de mojtahed et les institutions administratives et judiciaires contrôlées par l'état. De surcroît, l'auteur n'essaie pas d'inscrire son étude des procédures légales dans le domaine plus large de l'histoire sociale de Téhéran - le choix du contexte urbain téhéranais, annoncé dans l'introduction et dans le premier chapitre, n'est pas justifié par une mise en exergue des spécificités du panorama institutionnel de Téhéran. Finalement, l'auteur associe le ressentiment des oulémas contre les aléas de la jurisprudence qajar avec leur rôle important dans le mouvement constitutionnel iranien (p. 71) ce qui paraît être, en l'absence d'une analyse approfondie, un jugement plutôt hasardeux.

Néanmoins, cet ouvrage reste d'une importance fondamentale pour tous ceux qui s'intéressent à l'histoire du droit musulman et ouvre plusieurs pistes de recherche en histoire sociale de l'Iran qajar.

\section{AUTEURS}

\section{ALISA SHABLOVSKAIA}

Doctorante Sorbonne Nouvelle, Mondes iranien et indien, Paris 